\title{
Child Abuse and Mental Disorders in Iranian Adolescents
}

\author{
Azar Pirdehghan, ${ }^{1, *}$ Mahmood Vakili, ${ }^{2}$ Yavar Rajabzadeh, ${ }^{2}$ Mohammad Puyandehpour, ${ }^{2}$ and \\ Arezoo Aghakoochak ${ }^{3}$ \\ ${ }^{1}$ Department of Community and Preventive Medicine, Hamadan University of Medical Sciences, Hamadan, IR Iran \\ ${ }^{2}$ Department of Community and Preventive Medicine, Yazd, IR Iran \\ ${ }^{3}$ Health Monitoring Research Center, Shahid Sadoughi University of Medical Sciences, Yazd, IR Iran \\ *Corresponding author:Azar Pirdehghan, Department of Community and Preventive Medicine, Hamadan University of MedicalSciences, Hamadan, IR Iran. E-mail: azar_pirdehghan@yahoo.com
}

Received 2015 August 14; Accepted 2015 October 13.

\begin{abstract}
Background: Child abuse is a serious social health problem all over the world with important adverse effects.

Objectives: The aim of this study was to extend our understanding of the relation between mental disorders and child abuse.

Materials and Methods: The study was designed as a cross-sectional survey on 700 students in secondary schools using multiple cluster sampling in Yazd, Iran in 2013. We applied 2 self reported questionnaires: DASS (depression anxiety stress scales)-42 for assessing mental disorders (anxiety, stress and depression) and a standard self-reported valid and reliable questionnaire for recording child abuse information in neglect, psychological, physical and sexual domains. The collected data was analyzed using SPSS software. P-values $<0.05$ were considered as significant.

Results: There was a statically significant correlation between mental disorder and child abuse score(Spearman rho: 0.2; P-value <0.001) The highest correlations between mental disorders and child abuse were found in psychological domain, Spearman's rho coefficients were $0.46,0.41$ and 0.36 for depression, anxiety and stress respectively (P-value $<0.001$ ). Based on the results of logistic regression for mental disorder, females, last born adolescents and subjects with drug or alcohol abuser parents had mental disorder odds of 3,0.4 and 1.9 times compared to others; and severe psychological abuse, being severely neglected and having sexual abuse had odds 90, 1.6 and 1.5 respectively in another model.

Conclusions: Programming for mandatory reporting of child abuse by physicians and all health care givers e.g. those attending schools or health centers, in order to prevent or reduce its detrimental effects is useful and success in preventing child abuse could lead to reductions in the prevalence of mental disorders.
\end{abstract}

Keywords: Child Abuse, Child Neglect, Mental Health

\section{Introduction}

Child abuse is a serious social health problem all over the world with important adverse effects. This is an issue concerning millions of children and families which influence significantly children of any ethnicity, color, social status and religion and encompasses all ages (before birth, in infancy, childhood, adolescence, etc.) (1).

Prevalence estimations of child abuse are different worldwide. In Iran this is in the range of 4.7 to $91.6 \%$ according to the type of maltreatment and place of study (2-5). Relationship between child abuse and mental disorder is well known in different countries (6-9).

Evidence shows that child abuse and neglect are related to various disorders in adolescence, which include mental disorders, psychological and behavioral disorders, substance abuse, and poor physical health (10-14). Results in one review found emotional, sexual and physical child abuse as the most serious risk factors for depression. And sexual child abuse and family violence as the greatest risk factors for anxiety disorders (15). Other studies assessed the association between childhood sexual abuse and major depression and anxiety at higher age, and found that severe forms of sexual abuse were correlated with a greater risk of outcomes (16-19).

\section{Objectives}

In Iran, our knowledge about various effects associated with child abuse types and specific mental disorders is not sufficient. Our overall objective was to extend our understanding of the relation between mental conditions including anxiety, stress and depression, and child abuse and neglect. Maybe dispelling this gap in knowledge would disclose findings that could be as an alarm for health professionals and decision makers for prevention and intervention programming aimed at reducing both child abuse and poor mental health outcomes in adolescents.

Copyright (C) 2016, Growth \& Development Research Center. This is an open-access article distributed under the terms of the Creative Commons Attribution-NonCommercial 4.0 International License (http://creativecommons.org/licenses/by-nc/4.0/) which permits copy and redistribute the material just in noncommercial usages, provided the original work is properly cited. 


\section{Materials and Methods}

In 2013, we conducted a cross-sectional survey in two secondary school levels (6th and 7th level) in Yazd province located in central Iran. Students in consenting schools were in randomly multiple cluster selected classes. Of the 745 students from 25 classes eligible to participate, 700 completed the questionnaire with a response rate of $94 \%$.

We applied a self reported questionnaire consisting of 2 parts. The first part of the questionnaire included 20 demographic questions. In the second part a standard self-reported, valid and reliable (minimum internal consistency for sexual domain $\alpha$ : 0.87) questionnaire was applied for recording child abuse information in neglect, psychological, physical and sexual domains (20). All questions could be answered by a 4-level scale (never, sometimes, often and almost always). To score the questionnaire, children with positive answer to at least one question in each domain of emotional, physical and neglect were considered victims of that domain; children with positive answers to at least one question in each domain of emotional, physical and neglect were included in the total number of child abuse victims of all domains.

Another questionnaire used for measuring mental health situation among the adolescents was DASS (Depression Anxiety Stress Scales)-42. The DASS is a 42-item self report instrument designed to measure the three related negative emotional states of depression, anxiety and tension/stress in adolescents. DASS is made up of 42 self-report items to be completed over five to ten minutes, each reflecting a negative emotional symptom. Each of these is rated on a four-point Likert scale of frequency or severity of the participant's experiences over the last week with the intention of emphasizing states over traits. These scores ranged from 0 , meaning that the subject believed the item "did not apply to him at all", to 3, meaning that the subject considered the item to "apply to him very much, or most of the time" (21). In Iran validity and reliability of DASS-42 questionnaire were assessed (22). Correlation coefficient with Beck Anxiety Inventory and Beck Depression Inventory was 0.81 and 0.74 and Alpha coefficient for depression, anxiety and stress $0.94,0.85$ and 0.87 respectively (23). Adolescents with scores less than 9,7 and 14 for depression, anxiety and stress were considered as normal by coding zero in dependent outcome, and the other scores as faced with mental disorders by coding one in logistic regression model.

Mental health and child abuse questionnaire score could vary from 0 to 126 , and 38 to 152 respectively. In both of them the higher score indicated the worst situations. A percentage mode was used to describe the nominal data. The collected data was analyzed using SPSS software and chi-square test, independent t-test and logistic regression analysis.
In order to identify predicting factors for mental disorders in students, logistic regression analysis was used. In the univariate analyses, each variable was entered separately, and in the last step for multivariate analyses, those variables were entered which were significant in the univariate analyses to find the set of best predictors of mental disorders in adolescents using forward conditional model.

Considering the importance of the issue and the necessity of taking students' satisfaction and trust to cooperate honestly in responding to the questions, at first, nature and purpose of the questionnaire were clarified for students and anonymity was also emphasized.

\section{Results}

Of the 700 respondents aged 12 to 18 years (mean 13.3 years; SD 0.9 ), 57\% were females. The majority (92.8\%) of students did not have another job and few (3.8\%) of them said they used alcohol or drug. Among the adolescents $6.5 \%$ were single child in the family whereas $40.7 \%, 21.7 \%$ and 31.1\% were first, mid and last born, respectively. Other aspects of the family environment are summarized in Table 1.

Mean mental disorder score was 30.8 \pm 24.1 (range: 0 - 119) and it was $56.1 \pm 6.5$ (range: 38 - 81) for child abuse. There was a statically significant correlation between mental disorder and child abuse score (Spearman rho: correlation coefficient $=0.2 ;$ P-value $<0.001)($ Figure 1$)$.

Table 1. Family Environment Characteristics of Adolescents Including Cross-Sectional Study of Relationship Between Child Abuse and Mental Disorders in Iranian Adolescents

\begin{tabular}{|lc}
\hline Variable & Values $^{\mathbf{a}}$ \\
\hline Parents marital status $(\mathbf{n}=\mathbf{6 5 6})$ & $637(97.1)$ \\
\hline Living together & $19(2.9)$ \\
\hline Divorced or separated & \\
\hline Parents alive $(\mathbf{n}=\mathbf{6 6 5})$ & $617(92.8)$ \\
\hline Both alive & $44(6.6)$ \\
\hline Father died & $4(0.6)$ \\
\hline Mother died & $75(11.1)$ \\
\hline Mother's level of education $(\mathbf{n}=\mathbf{6 7 8})$ & $603(88.9)$ \\
\hline University educated & $120(17.6)$ \\
\hline High school Diploma or less & $561(82.4)$ \\
\hline Father's level ofeducation $(\mathbf{n}=\mathbf{6 8 1})$ & \\
\hline University educated & \\
\hline High school Diploma or less & \\
\hline Parental drug and/or alcohol abuse $(\mathbf{n}=\mathbf{6 7 7})$ & \\
\hline Yes & \\
\hline a & \\
\hline Data are presented as No. (\%).4)
\end{tabular}




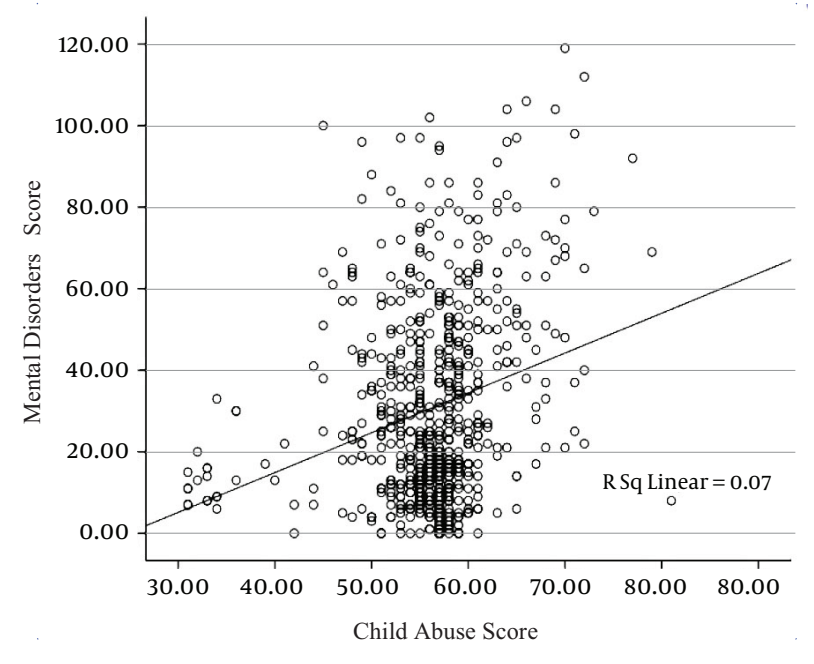

Figure 1. Correlation Between Mental Disorders and Child Abuse Score in Iranian Adolescents
The highest correlation between mental disorders and child abuse was found in psychological domain, Spearman's rho coefficients were $0.46,0.41$ and 0.36 for depression, anxiety and stress respectively (P-value $<0.001)$. Other coefficients for correlation between mental disorder (i.e. depression, anxiety and stress) and four domains of child abuse are shown in Table 2 .

Among adolescents with experience of at least one type of child abuse, suffering from some degree of depression was $45.3 \%$ vs $6.8 \%$ in adolescents without it. It was $43.1 \%$ vs 8.9 and $39.7 \%$ vs $4.5 \%$ for anxiety and stress respectively. There were statically significant relationships between severity of different types of mental disorders and experience of at least one type of child abuse (chi square: Pvalue $<0.001$ ) (Table 3 ).

Based on the results of simple logistic regression for mental disorder, related variables including type of school (governmental/non profit), sex, birth order, student's or parent's substance abuse and parents living situation in model 1 and four domains of disorders (All $\mathrm{P}<0.05$ ), were candidates to enter in the multivariate analysis in two models.

Table 2. Correlations Between Mental Disorders and Child Abuse Domains in Iranian Adolescents

\begin{tabular}{lccc}
\hline Spearman's rho $^{\mathbf{a}}$ & Depression & Anxiety & Stress \\
\hline Psychological abuse & .461 & .413 & .364 \\
Neglect & .376 & .269 & .248 \\
Physical abuse & .289 & .260 & .182 \\
Sexual abuse & .241 & .216 & .218 \\
\hline
\end{tabular}

$\mathrm{a}_{\mathrm{P} \text { value }}<0.001$ for all correlations.

\begin{tabular}{lcc}
\hline Table 3. Frequency of Mental Disorders Severity According to Child Abuse Experience in Iranian Adolescents ${ }^{\mathrm{a}}$ & No & Yes \\
\hline Mental Disorder/Child Abuse Experience & & $344(54.7)$ \\
\hline Depression & $41(93.2)$ & $66(10.5)$ \\
\hline Normal & $1(2.3)$ & $105(16.7)$ \\
\hline Mild & $2(4.5)$ & $114(18.1)$ \\
\hline Moderate & 0 & $360(56.9)$ \\
\hline Severe and very severe & $41(91.1)$ & $60(9.5)$ \\
\hline Anxiety & $2(4.4)$ & $100(15.8)$ \\
\hline Normal & $1(2.2)$ & $113(17.8)$ \\
\hline Mild & $1(2.2)$ & $381(60.3)$ \\
\hline Moderate & & $77(12.2)$ \\
\hline Severe and very severe & $42(95.5)$ & $99(15.7)$ \\
\hline Stress & $1(2.3)$ & $75(11.8)$ \\
\hline Normal & $1(2.3)$ & 0 \\
\hline Mild & & \\
\hline Moderate & & \\
\hline Severe and very severe & & \\
\hline
\end{tabular}

\footnotetext{
${ }^{\mathrm{a}}$ Chi square: $\mathrm{P}$ value $<0.001$.
} 
However, of the above mentioned variables, sex, birth order, parent's substance abuse in model 1 and neglect severity, emotional abuse severity and having experience of sexual abuse (All $\mathrm{P}<0.05$ ) in model 2, were significant in the multivariate analysis. Based on these results, females, last born adolescents and subjects with parental drug or alcohol abuse had mental disorder odds of 3, 0.4 and 1.9 times compared to others. Odds of mental disorder for students with child abuse and neglect in various severities are shown in Table 4.

Table 4. Results of Multiple Logistic Regressions Analysis of Mental Disorders Related to Variables and Child Abuse and Neglect

\begin{tabular}{|c|c|c|c|c|}
\hline Variables & OR & Lower & Upper & P-value \\
\hline \multicolumn{5}{|l|}{ Model. $^{\mathrm{a}}$} \\
\hline \multicolumn{5}{|l|}{ Gender } \\
\hline Female & 3 & 1.8 & 4.8 & $<0.001$ \\
\hline Male & referent & NA & NA & NA \\
\hline \multicolumn{5}{|c|}{$\begin{array}{l}\text { Parental drug } \\
\text { or alcohol use }\end{array}$} \\
\hline No & referent & NA & NA & NA \\
\hline Yes & 1.9 & 1.1 & 3.2 & 0.01 \\
\hline \multicolumn{5}{|l|}{ Birth order } \\
\hline Single child & 2 & 0.8 & 4.7 & 0.1 \\
\hline First born & 0.8 & 0.4 & 1.4 & 0.5 \\
\hline Last born & 0.4 & 0.2 & 0.8 & 0.009 \\
\hline Mid born & referent & NA & NA & NA \\
\hline \multicolumn{5}{|l|}{ Model.2 b } \\
\hline \multicolumn{5}{|c|}{$\begin{array}{l}\text { Psychological } \\
\text { abuse severity }\end{array}$} \\
\hline No & referent & NA & NA & NA \\
\hline Mild & 2.9 & 1.5 & 5.5 & 0.001 \\
\hline Moderate & 12.7 & 5.5 & 24 & $<0.000$ \\
\hline Severe & 90 & 9.2 & 888 & $<.000$ \\
\hline \multicolumn{5}{|c|}{ Neglect severity } \\
\hline No & referent & NA & NA & NA \\
\hline Mild & 2.7 & 1.2 & 6.3 & .015 \\
\hline Moderate & 4.9 & 2 & 12 & $<.001$ \\
\hline Severe & 1.6 & 0.4 & 5.5 & .4 \\
\hline \multicolumn{5}{|l|}{ Sexual abuse } \\
\hline No & referent & NA & NA & NA \\
\hline Yes & 1.5 & 1.04 & 2.3 & .03 \\
\hline
\end{tabular}

Abbreviation: NA, not available.

${ }^{a}$ Model.1: Hosmer and Lemeshow test: Chi square $(6)=1.4$, P-value $=$ 0.96 ; A total of $76.8 \%$ of subjects were correctly classified.

b Model.2: Hosmer and Lemeshow test: Chi square (7) = 6.3, P-value = 0.5; A total of $78.8 \%$ of subjects were correctly classified.

\section{Discussion}

We found strong association between child abuse and mental conditions. In our study, 93.5\% of the adolescents had experienced at least one type of neglect, psy- chological, physical and sexual abuse ranging mild to severe. All 4 types of child abuse and neglect were associated with all types of mental disorders including depression, anxiety and stress. Neglect, psychological and sexual abuse were considered strongly as predictors of mental disorders.

The current findings are also consistent with other studies that found relations with specific types of child abuse and mental conditions (6, 24-30), although relationship between assessment of child abuse and mental disorders is not directly comparable because of diversity in instruments or methods.

A review from Canada reported that all types of abuse are damaging to children physically, emotionally, and psychologically and can cause long-term difficulties with behavior and mental health development (6). In a population-based survey of 1000 children and adolescents aged 10 - 17 years in the USA, a linear relationship between multiple victimization and other childhood disorders as well as adolescent depression and anger/aggression was shown (31).

In the present study the highest correlation scores for all mental disorders (depression, anxiety and stress) were found in psychological domain. In a prospective cohort study childhood neglect was considered as unique predictor of major depression (27). Another study emphasized the effect of sexual abuse on depression and chronic pain in adulthood and revealed that the more severe the abuse, the stronger was the association with poor outcomes in adulthood (32). Our results similarly showed a dose-dependent relationship between psychological abuse with mental disorders so that the severe type predicted mental disorders 30 times more than the mild kind in logistic regression model. In the model other variables including sex, birth order and drug or alcohol abuse by parents were considered as predictors of mental disorders.

Females had mental disorder odds of 3 times compared to males. The finding was similar to the results of other studies on Iranian adolescents which showed that mental disorders, in particular depression and anxiety, were more prevalent in females $(33,34)$.

Among siblings, the lowest rank position appeared to be a protective factor against the development of mental disorders. Many studies showed that a higher rank position in the birth order was positively associated with higher risk (35). One study concluded that being the middle child and living with both biological parents appeared to be protective factor against the development of emotional disorders or attention deficit hyperactivity disorders (ADHD) (36).

We found that alcohol and/or substance abuse by parents predicted depression, anxiety and stress symptoms in adolescents. This result is parallel with a lot of studies which mentioned the effect of parental addiction on psychological, emotional and behavioral disorders on children (37-39). 


\subsection{Conclusion}

Our findings show that 93.5\% of the adolescents in Yazd, Iran have experienced at least one mild type of child abuse and neglect and that child abuse has strong relationship with mental conditions. Generally child abuse is an important public health disorder in Iran as well as other parts of the world. It is notable that in some societies child abuse and neglect is perceived in terms of very harsh physical assault and sometimes this behavior is considered necessary for punishment of the child (40). So awareness of health care providers about child abuse and its association with mental disorders is needed. Child abuse should be considered and explored by psychologists who encounter adolescents with mental disorders (i.e., depression, anxiety and stress).

Mandatory reporting of child abuse by all care givers e.g. those attending schools, in order to prevent or reduce its detrimental effects, is useful. In addition, success in preventing child abuse could lead to reductions in the prevalence of mental disorders.

\subsection{Strengths and Limitations}

In the present study several types of child abuse and mental conditions were assessed. However, the data from this study were cross-sectional and retrospective in nature. It is probable that some reported types of abuse especially emotional and neglect were due to some mental disorders like depression. Another limitation was that mental disorders were assessed only using self reported questionnaires. Moreover many other important mental disorders (e.g., personality disorders) could be included in the study.

\section{Acknowledgments}

We are grateful to staff and administration of Yazd social harm prevention center in department of education for the rendered support. This article is derived of a MD thesis in Medical School of Shahid Sadoughi university of medical sciences.

\section{References}

1. Weru MW. Impact of violent conflict on pre-school children (a case of 2007-2008 post election violence in Kibera, Kenya). Nairobi : University of Nairobi; 2013.

2. Eslami-Shahrbabaki M, Haghdoost A, Sabzevari L, Eslami-Shahrbabaki A, Kalantari M. Prevalence of Child Abuse in 15-17 year old Students. Zahedan J Res Med Sci. 2014;16(5):11-5.

3. Mahram M, Hosseinkhani Z, Nedjat S, Aflatouni A. Epidemiologic evaluation of child abuse and neglect in school-aged children of qazvin province, iran. Iran J Pediatr. 2013;23(2):159-64. [PubMed: 23724176]

4. Sheikhattari P, Stephenson R, Assasi N, Eftekhar H, Zamani Q Maleki B, et al. Child maltreatment among school children in the Kurdistan Province, Iran. Child Abuse Negl. 2006;30(3):231-45. doi: 10.1016/j.chiabu.2005.10.009. [PubMed:16524629]

5. Mohammadi MR, Zarafshan H, Khaleghi A. Child Abuse in Iran: a systematic review and meta-analysis. Iran I Psychiatry. 2014;9(3):118-24. [PubMed:25561950]

6. Afifi TO, MacMillan HL, Boyle M, Taillieu T, Cheung K, Sareen J.Child abuse and mental disorders in Canada. CMAJ. 2014;186(9):E32432. doi: 10.1503/cmaj.131792. [PubMed: 24756625]

7. Afifi TO, Mota NP, Dasiewicz P, MacMillan HL, Sareen J. Physical punishment and mental disorders: results from a nationally representative US sample. Pediatrics. 2012;130(2):184-92. doi: 10.1542/ peds.2011-2947. [PubMed: 22753561]

8. Scott KM, Smith DR, Ellis PM. Prospectively ascertained child maltreatment and its association with DSM-IV mental disorders in young adults. Arch Gen Psychiatry. 2010;67(7):712-9. doi:10.1001/ archgenpsychiatry.2010.71. [PubMed: 20603452]

9. Kessler RC, McLaughlin KA, Green JG, Gruber MJ, Sampson NA, Zaslavsky AM, et al. Childhood adversities and adult psychopathology in the WHO World Mental Health Surveys. Br J Psychiatry. 2010;197(5):378-85. doi: 10.1192/bjp.bp.110.080499. [PubMed: 21037215]

10. Bonomi AE, Cannon EA, Anderson ML, Rivara FP, Thompson RS. Association between self-reported health and physical and or sexual abuse experienced before age 18. Child Abuse Negl. 2008;32(7):693-701. doi: 10.1016/j.chiabu.2007.10.004. [PubMed: 18602692]

11. Cohen P, Brown J, Smaile E. Child abuse and neglect and the development of mental disorders in the general population. Dev Psychopathol. 2001;13(4):981-99. [PubMed:11771917]

12. Lynskey MT, Fergusson DM. Factors protecting against the development of adjustment difficulties in young adults exposed to childhood sexual abuse. Child Abuse Negl. 1997;21(12):1177-90. [PubMed: 9429770]

13. McLeer SV, Dixon JF, Henry D, Ruggiero K, Escovitz K, Niedda T, et al. Psychopathology in non-clinically referred sexually abused children. J Am Acad Child Adolesc Psychiatry. 1998;37(12):1326-33. doi:10.1097/00004583-199812000-00017. [PubMed: 9847506]

14. Shonkoff JP, Boyce WT, McEwen BS. Neuroscience, molecular biology, and the childhood roots of health disparities: building a new framework for health promotion and disease prevention. JAMA. 2009;301(21):2252-9. doi: 10.1001/jama.2009.754. [PubMed: 19491187]

15. De Venter M, Demyttenaere K, Bruffaerts R. [The relationship between adverse childhood experiences and mental health in adulthood. A systematic literature review]. Tijdschr Psychiatr. 2013;55(4):259-68. [PubMed: 23595840]

16. Bebbington P, Jonas S, Kuipers E, King M, Cooper C, Brugha T, et al. Childhood sexual abuse and psychosis: data from a cross-sectional national psychiatric surveyin England. BrJPsychiatry.2011;199(1):2937. doi:10.1192/bjp.bp.110.083642. [PubMed: 21508437]

17. Fergusson DM, McLeod GF, Horwood LJ. Childhood sexual abuse and adult developmental outcomes: findings from a 30-year longitudinal study in New Zealand. Child Abuse Negl. 2013;37(9):66474. doi:10.1016/j.chiabu.2013.03.013. [PubMed: 23623446]

18. Kendler KS, Aggen SH. Clarifying the causal relationship in women between childhood sexual abuse and lifetime major depression. Psychol Med. 2014;44(6):1213-21. doi: 10.1017| So033291713001797. [PubMed: 23942036]

19. Cutajar MC, Mullen PE, Ogloff JR, Thomas SD, Wells DL, Spataro J. Psychopathology in a large cohort of sexually abused children followed up to 43 years. Child Abuse Negl. 2010;34(11):813-22. doi: 10.1016/j.chiabu.2010.04.004. [PubMed:20888636]

20. Mohammadi MR. Development, validation and reliability of child abuse self report scale (CASRS) in iranian students. Med J Islam Republic Iran. 2003;(17):51-8.

21. Osman A, Wong JL, Bagge CL, Freedenthal S, Gutierrez PM, Lozano G. The Depression Anxiety Stress Scales-21 (DASS-21): further examination of dimensions, scale reliability, and correlates. J Clin Psychol. 2012;68(12):1322-38. doi: 10.1002/jclp.21908. [PubMed: 22930477]

22. Afzali A, Delavar A, Borjali A, Mirzamani M. Psychometric properties of DASS-42 as assessed in a sample of Kermanshah High School students. J Res Behav Sci . 2007;5(2):91-2.

23. Rood E, Mehdizadeh M, Hashemi T. Comparison of Attachment Styles Depression and Anxiety of Students. Int J Psychol Behav Res. 2014;1(1):212.

24. Nguyen HT, Dunne MP, Le AV. Multiple types of child maltreatment and adolescent mental health in Viet Nam. Bull World 
Health Organ. 2010;88(1):22-30. doi: 10.2471/BLT.08.060061. [PubMed: 20428350]

25. Springer KW, Sheridan J, Kuo D, Carnes M. Long-term physical and mental health consequences of childhood physical abuse: results from a large population-based sample of men and women. Child Abuse Negl. 2007;31(5):517-30. doi: 10.1016/j.chiabu.2007.01.003. [PubMed:17532465]

26. Kiser LJ, Stover CS, Navalta CP, Dorado J, Vogel JM, Abdul-Adil JK, et al. Effects of the child-perpetrator relationship on mental health outcomes of child abuse: it's (not) all relative. Child Abuse Negl. 2014;38(6):1083-93. doi: 10.1016/j.chiabu.2014.02.017. [PubMed: 24661693]

27. Nikulina V, Widom CS, Czaja S. The role of childhood neglect and childhood poverty in predicting mental health, academic achievement and crime in adulthood. Am J Community Psychol. 2011;48(3-4):309-21. doi: 10.1007/s10464-010-9385-y. [PubMed: 21116706]

28. Afifi TO, Enns MW, Cox BJ, Asmundson GJ, Stein MB, Sareen J. Population attributable fractions of psychiatric disorders and suicide ideation and attempts associated with adverse childhood experiences. Am J Public Health. 2008;98(5):946-52. doi: 10.2105 AJPH.2007.120253. [PubMed:18381992]

29. Molnar BE, Buka SL, Kessler RC. Child sexual abuse and subsequent psychopathology: results from the National Comorbidity Survey. Am J Public Health. 2001;91(5):753-60. [PubMed:11344883]

30. MacMillan HL, Boyle MH, Wong MY, Duku EK, Fleming JE, Walsh CA. Slapping and spanking in childhood and its association with lifetime prevalence of psychiatric disorders in a general population sample. CMAJ.1999;161(7):805-9. [PubMed:10530296]

31. Turner HA, Finkelhor D, Ormrod R. The effect of lifetime victimization on the mental health of children and adolescents. Soc Sci Med. 2006;62(1):13-27. doi: 10.1016/j.socscimed.2005.05.030. [PubMed: 16002198]

32. Arnow BA. Relationships between childhood maltreatment, adult health and psychiatric outcomes, and medical utilization.
J Clin Psychiatry. 2004;65 Suppl 12:10-5. [PubMed: 15315472]

33. AKKASHEH GH. Assessing the mental health of university students in Kashan Medical Sciences University. Iran J Psychiatry Clin Psychol.2000;5(4):11-7.

34. Basirnia A, Sharifi V, Mansouri N, Mesgarpour B, Mohammadi $\mathrm{MR}$, Amini H, et al. Prevalence of mental disorders among highschool students in Iran: a systematic review. Iran J Psychiatr 2009;4(1):1-6.

35. Bjorngaard JH, Bjerkeset O, Vatten L, Janszky I, Gunnell D Romundstad P. Maternal age at child birth, birth order, and suicide at a young age: a sibling comparison. Am J Epidemiol. 2013;177(7):638-44. doi:10.1093/aje/kwt014. [PubMed:23479347]

36. Carballo IJ, Garcia-Nieto R, Alvarez-Garcia R, Caro-Canizares I Lopez-Castroman J, Munoz-Lorenzo L, et al. Sibship size, birth order, family structure and childhood mental disorders. Soc Psychiatry Psychiatr Epidemiol. 2013;48(8):1327-33. doi:10.1007/s00127013-0661-7. [PubMed: 23407902]

37. Stanger C, Higgins ST, Bickel WK, Elk R, Grabowski J, Schmitz J, et al. Behavioral and emotional problems among children of cocaine- and opiate-dependent parents. J Am Acad Child Adolesc Psychiatry. 1999;38(4):421-8. doi: 10.1097/00004583-199904000 00015. [PubMed:10199114]

38. Kelley ML, Fals-Stewart W. Psychiatric disorders of children living with drug-abusing, alcohol-abusing, and non-substance-abusing fathers. J Am Acad Child Adolesc Psychiatry. 2004;43(5):621-8 doi:10.1097/0 0004583-200405000-00016. [PubMed: 15100569]

39. Nunes EV, Weissman MM, Goldstein RB, McAvay G, Seracini AM, Verdeli $\mathrm{H}$, et al. Psychopathology in children of parents with opiate dependence and/or major depression.J Am Acad Child Adolesc Psychiatry. 1998;37(11):1142-51. doi: 10.1097/00004583-19981100000013. [PubMed: 9808925 ]

40. Lau JT, Liu JL, Cheung JC, Yu A, Wong CK. Prevalence and correlates of physical abuse in Hong Kong Chinese adolescents: a population-based approach. Child Abuse Negl. 1999;23(6):549-57. [PubMed: 10391512] 